\title{
Analysis of salivary fluid and chemosensory functions in patients treated for primary malignant brain tumors
}

\author{
Susan Mirlohi • Susan E. Duncan • Michele Harmon • \\ Doug Case • Glenn Lesser • Andrea M. Dietrich
}

Received: 17 July 2013 / Accepted: 5 February 2014 / Published online: 5 March 2014

(C) The Author(s) 2014. This article is published with open access at Springerlink.com

\begin{abstract}
Objectives The frequency and causes of chemosensory (taste and smell) disorders in cancer patients remain under-reported. This study examined the impact of cancer therapy on taste/ smell functions and salivary constituents in brain tumor patients.

Materials and methods Twenty-two newly diagnosed patients with primary malignant gliomas underwent 6 weeks of combined modality treatment (CMD) with radiation and temozolomide followed by six monthly cycles of temozolomide. Chemosensory functions were assessed at $0,3,6,10,18$, and 30 weeks with paired samples of saliva collected before and after an oral rinse with ferrous-spiked water. Iron $(\mathrm{Fe})$ induced oxidative stress was measured by salivary lipid oxidation (SLO); salivary proteins, electrolytes, and metals were determined. Parallel salivary analyses were performed on 22 healthy subjects.

Results Chemosensory complaints of cancer patients increased significantly during treatment $(p=0.04)$ except at 30 weeks. Fe-induced SLO increased at 10 and 18 weeks.
\end{abstract}

S. Mirlohi • A. M. Dietrich $(\bowtie)$

Department of Civil and Environmental Engineering, Virginia Tech, Blacksburg, VA, USA

e-mail: andread@vt.edu

S. E. Duncan · A. M. Dietrich

Department of Food Science and Technology, Virginia Tech, 413

Durham Hall, 0246, Blacksburg, VA 24061-0246, USA

\section{Harmon · G. Lesser}

Department of Internal Medicine-Section of Hematology and Oncology, Wake Forest School of Medicine, Winston-Salem, NC, USA

D. Case

Division of Public Health Sciences, Wake Forest School of Medicine, Winston-Salem, NC, USA
When compared with healthy subjects, SLO, total protein, $\mathrm{Na}$, $\mathrm{K}, \mathrm{Cu}, \mathrm{P}, \mathrm{S}$, and $\mathrm{Mg}$ levels, as averaged across all times, were significantly higher $(p<0.05)$, whereas salivary $\mathrm{Zn}, \mathrm{Fe}$, and oral $\mathrm{pH}$ levels were significantly lower in cancer patients $(p<0.05)$. Neither time nor treatment had a significant impact on these salivary parameters in cancer patients.

Conclusions Impact of CMT treatment on chemosensory functions can range from minimal to moderate impairment. Analysis of SLO, metals, and total protein do not provide for reliable measures of chemosensory dysfunctions over time. Clinical relevance Taste and smell functions are relevant in health and diseases; study of salivary constituents may provide clues on the causes of their dysfunctions.

Keywords Metallic flavor - Oral lipid oxidation - Cancer . Brain tumor $\cdot$ Chemotherapy $\cdot$ Saliva $\cdot$ Taste and smell

\section{Introduction}

Chemosensory (taste and smell) functions are critical aspects of human physiology. They provide us with the pleasures of experiencing flavors and aromas in foods and beverages and the smells of fragrances. They also protect us from the dangers of ingested or inhaled toxins. Thus, disorders of taste and smell functions can have important health implications as well as debilitating effects on our quality of life. Factors associated with taste and smell disorders include aging, environmental exposure, nasal congestion and allergies, prescription medication, head trauma, neurological diseases such as Alzheimer's, and cancer [1-6].

In cancer patients, taste and smell disorders have been associated with the disease itself and/or the effects of chemo- and radiation therapies [7]. Taste disorders have been described as "nauseating" or "unpleasant" by cancer patients of all ages, including pediatric patients [8-10]. These issues 
have broad impacts on the quality of life for these patients and often lead to other implications such as reduced oral intake and nutritional deficiency, weight loss, and depression [11-13]. While these problems are significant, there are only a limited number of studies exploring their causes and possible treatments.

Among taste disorders, perception of a persisting metallic and bitter taste or aftertaste in the mouth is the most common disorder described by cancer patients [14]. Sensory perception of metallic off-flavors from ingested foods and beverages is caused by the release of retronasal odors associated with volatile by-products of metal-oxidized lipids within the oral cavity. Metal-induced lipid oxidation also occurs in the oral cavity of healthy human subjects when potable water spiked with copper $(\mathrm{Cu})$ and iron $(\mathrm{Fe})$ is consumed [15-18]. On the human skin surface, lipid oxidation has been linked to the production of "metallic" odor compounds produced when a metallic object such as a key or a penny is held in the hand [19]. Within the oral cavity, polyunsaturated fatty acids in the oral mucosal cell membranes or the salivary fluid lipids can be oxidized to form by-products of lipid oxidation [20]. In cancer patients, occurrence of metallic and bitter taste sensations has been associated with exposure to low levels of irradiation and chemotherapy [21-23]. Release of chemotherapy drugs into the salivary fluid and interaction with taste buds can cause impairments by direct contact with taste receptor cells. Additionally, damage to sensory nerves such as the chorda tympani can cause disturbances in taste functions [24]. As side effects of treatment, taste and smell abnormalities are most commonly reported in head and neck cancer cases [25, 26], which include cancers of the organs in the regions of the throat, nasal/oral cavities, and salivary glands [27]. Abnormal taste and smell symptoms are anticipated in other types of cancers where sensory organs are affected by the field of radiation treatment, as is the case for primary malignant brain tumors or gliomas. Currently, the most common treatment for such tumors is surgery, followed by concurrent radiation and chemotherapy - typically an orally administered drug called temozolomide (Temodar). Temozolomide is then given on monthly cycles for 6-12 months as maintenance therapy [28].

The Central Brain Tumor Registry of the US has reported that approximately 24,000 new primary malignant brain tumors are diagnosed in the USA each year [29]. Although most prevalent among the elderly (greater than 50 years of age), brain tumors occur in all ages and are the second most frequent malignancy of childhood after leukemia [29]. Currently, no prospective data are available on the incidence, severity or duration of the taste and smell abnormalities experienced by brain tumor patients undergoing concurrent radiation and chemotherapy. Anecdotally, a large number of these patients develop dramatic alterations in perception of food flavor, texture, quality, and the sensation of a lingering metallic taste within several weeks of beginning radiation therapy, with or without concurrent chemotherapy [30]. These alterations lead to food aversion, weight loss, and a profoundly decreased quality of life $[2,12]$. They may last for up to several months after the radiation has been completed and, on occasion, normal taste and odor sensation never returns [2]. The objectives of this study were (1) to quantify taste and smell abnormalities in a small cohort of newly diagnosed primary glioma patients treated with combined modality treatment (CMT); (2) to assess the etiologic role of salivary oxidative stress and constituents, as cause of the observed sensory changes; and (3) to compare the salivary constituents in the cancer patients with healthy subjects. It is hoped that the findings from this research will provide baseline data and lead to future trials utilizing an intervention to prevent or treat taste and smell disturbances in similar patient populations.

\section{Materials and methods}

Human subjects This study was approved by the Institutional Review Board at Virginia Tech and the Wake-Forest School of Medicine. Twenty-two cancer patients (ten females), with ages ranging from 20 to 79 years (median age, 60), were recruited from the brain tumor clinic at the Comprehensive Cancer Center of Wake Forest University. Eligibility criteria included age greater than 18 years, a newly diagnosed primary malignant brain tumor, anticipated combined modality therapy, and an expected survival of at least 6 months. Ineligible patients included those with an extreme dry mouth syndrome that prevented them from producing adequate amounts of saliva (about $2 \mathrm{~mL}$ in 15-20 min), known HIV-positive status, and with any of the following conditions: untreated gastroesophageal reflux disease; uncontrolled diabetes; active oral infections including thrush; or evidence of active mucositis. Additionally, 22 healthy subjects (14 females), with ages ranging from 21 to 82 years (median age, 58), were recruited from the community, students, faculty, and staff of Virginia Tech and Blacksburg, Virginia. Healthy subjects were required to have no chronic oral or general health problems, be nonsmokers, and not pregnant. All subjects read and signed an informed consent form in accordance with the approved protocols.

Cancer treatment plan Cancer patients received a CMT, composed of standard radiation therapy with concurrent temozolomide, over 6 weeks followed by adjuvant temozolomide given for 5 days each month for an additional 6 months. Patients underwent an initial, baseline saliva analysis and chemosensory assessment prior to beginning CMT. Repeat analyses were performed following 3, 6, 10, 18, and 30 weeks of treatment. For healthy subjects, saliva analysis was performed at 0 (baseline), 3, 6, 10, 18, and 30 weeks. A schematic 
of cancer treatment regimen and saliva collection is depicted in Fig. 1. Among cancer patients, 17 subjects (seven females) had baseline and CMT (3-6 weeks) or post-CMT (10 weeks) measurements and were included in the data analysis. Most subjects provided data through 10 weeks, but not all patients were able to provide data at each time point and four dropped out after 10 weeks due to their disease progress. The numbers of subjects at $0,3,6,10,18$, and 30 weeks were $17,15,15,16$, 12 , and 12, respectively. Data were complete for the healthy subjects. One patient was a current smoker, but stopped smoking at the time of diagnosis; 5 patients were previous smokers who had stopped 5 to 30 years earlier, and the remaining patients were nonsmokers.

Saliva collection and analysis At baseline and each time point, saliva samples were collected from subjects (who had not consumed food or beverages and had not smoked for at least one hour prior to testing) as follows. First, subjects rinsed their mouth using purified water (Aquafina ${ }^{\circledR}$, which is treated by reverse osmosis and has chemical properties similar to distilled water). After a 1-minute rest, they sipped $2 \mathrm{~mL}$ of purified water, as the control sample, then, swished it around their mouth for $20 \mathrm{sec}$, and, without swallowing, expectorated saliva into a clean sample collection tube until approximately $4 \mathrm{~mL}$ of saliva (control) was collected. After a short rest period, subjects sipped $2 \mathrm{~mL}$ of ferrous sulfate (SigmaAldrich, PA, CAS \# 13463-43-g) solution (at $10 \pm 1 \mathrm{mg} / \mathrm{L}$ ferrous), swished the solution around their mouth, and expectorated the second (ferrous) $4 \mathrm{~mL}$ saliva sample. Subjects were asked to put on nose clips before sipping the metal salt solution to help evaluate the retronasal component of the metallic flavor sensation. Subjects' oral $\mathrm{pH}$ was measured using a $\mathrm{pH}$ indicator strip (Cen-Med/Fisher M95883) after sampling the control solution and again after sampling the ferrous salt solution. Saliva samples were frozen immediately and stored at $-50^{\circ} \mathrm{C}$ for up to 3 months until analysis. Saliva analysis included the measurement of Fe-induced salivary oxidative stress response as thiobarbituric acid reactive substances (TBARS), total protein, and specific metals, nonmetals, and electrolytes.

Fe-induced salivary oxidative stress response TBARS method was used for the measurement of salivary oxidative stress by lipid oxidation. The method was modified from Spanier's to work with liquid samples and to enhance readings at low concentrations [31]. For TBARS analysis, $1 \mathrm{~mL}$ of saliva sample and known concentrations of malondialdehyde (MDA) standard were mixed with $2 \mathrm{~mL}$ of thiobarbituric acid (TBA) solution and digested for $60 \mathrm{~min}$ at $95{ }^{\circ} \mathrm{C}$ in a water bath. Then, the samples were immediately cooled in an ice bath, mixed with $2 \mathrm{~mL}$ of $n$-butanol/pyridine mixture (at 15:1 ratio), and centrifuged for $15 \mathrm{~min}$. at a speed of $3,000 \times \mathrm{g}$. The absorbance of the supernatant was measured with a spectrophotometer at $532 \mathrm{~nm}$ for the samples and standard curve. The concentration of TBARS was obtained from the MDA standard curve and absorbance values. The dilution effect was taken into consideration in the calculations. As TBARS is a nonspecific indicator of MDA formation, one of several byproducts of lipid oxidation, the results were reported in $\mu \mathrm{M}$ units of TBARS rather than MDA.

For the purpose of data analysis and as an indicator for potentially heightened sensitivity to metallic flavor, Feinduced oxidative stress response was defined as the arithmetic difference between salivary lipid oxidation (SLO)
Fig. 1 Saliva collection and cancer treatment regimen. Study subjects donated saliva at time 0 , $3,6,10,18$, and 30 weeks. For cancer patients, time 0 represents the baseline (prior to the start of cancer treatment). Treatment designation for data plotting and analysis purposes include: 0 (no treatment or none), representing baseline or 0 time; 1 (CMT) representing 3-and 6-week times; 2 (post-CMT), representing 10week time; and 3 (Chemo), representing 18 - and 30-week times. CMT combined modality treatment

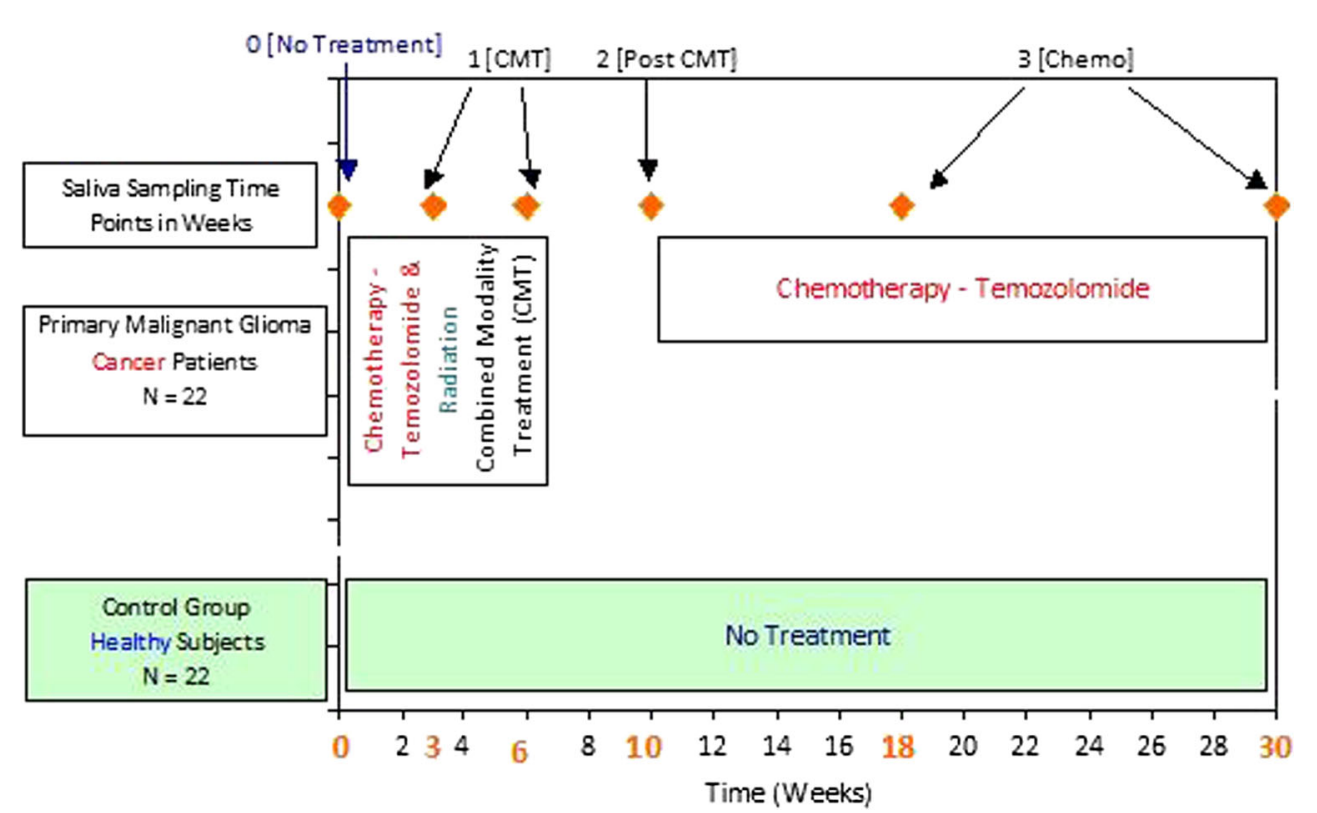


measured in saliva before and after the oral rinse with ferrous-spiked water.

Salivary protein As the protein content of saliva can vary among individuals, to report the TBARS results more accurately, the total protein content of the saliva of the patients, as well as the healthy individuals, was measured and the results were reported as $\mu \mathrm{M}$ TBARS produced per gram of protein. Total protein content of saliva was analyzed using the Bradford assay [32]. A standard curve was obtained by using bovine serum albumin at $1 \mathrm{mg} / \mathrm{mL}$ concentration. To perform the analysis, $1 \mathrm{~mL}$ of Bradford reagent was mixed with 8 to $20 \mu \mathrm{L}$ of saliva. The samples were vortexed and $100 \mu \mathrm{L}$ of the mixture was transferred to the well plates and read by spectrophotometer at $595 \mathrm{~nm}$. Duplicates of each sample were analyzed, and the total protein content of the saliva was determined from the standard curve.

Salivary metals, nonmetals, and electrolytes Saliva samples were first thawed at room temperature. Then, they were diluted with deionized water at 1:10 ratio and digested with trace metals grade nitric acid at $90{ }^{\circ} \mathrm{C}$ for $45 \mathrm{~min}$.; hydrogen peroxide was added and the solution was heated to $130{ }^{\circ} \mathrm{C}$ until the mixture became clear as described by the US Environmental Protection Agency method 3050B [33]. After digestion, the samples were adjusted back to their original dilution volume and acidified with $2 \%$ trace metals grade nitric acid prior to being analyzed by emission spectroscopy using Inductively Coupled Plasma technique [33].

Chemosensory assessment There are no standard tools specifically designed to assess taste and smell in cancer patients. Thus, as an exploratory endpoint, self-perceived taste and smell functions were assessed using a validated questionnaire that has been used to evaluate chemosensory functions in AIDS patients [34]. As part of the questionnaire, patients were asked to rate their individual taste and smell abnormalities as "insignificant," "mild," "moderate," "severe," or "incapacitating." The tool yields a taste complaint score (0-10) based on the subjects' responses to nine questions addressing changes to the sense of taste since the start of their cancer treatment. The questionnaire was completed prior to the start of treatment (baseline) and at 3,6,10,18, and 30-week time points following the baseline. For the taste complaint portion of the questionnaire, there were nine questions and scores could vary from 0 to 10 . To score the questionnaire, one point was added for each of four questions when the subject indicated an abnormal sensitivity to sweet, sour, salty or bitter. Four additional questions and a possible four points pertained to complaints about specific attributes of taste: (1) foods tasting differently, (2) drugs affecting taste, (3) bad taste in mouth, or (4) a change in the sense of taste. The ninth taste question addressed rating the severity of abnormality for the overall sense of taste. One point was added if the subject rated their overall taste abnormality as "mild" or "moderate"; two points were added if a rating of "severe" or "incapacitating" was reported. Similarly, a smell complaint score (0-6) was generated by adding one point for a positive response to each of five questions addressing self-perceived changes to the sense of smell. One additional point was assigned to the total smell complaint score, if a severity rating of "severe" or "incapacitating" was reported for the smell abnormality. The total chemosensory complaint score (CSCS; score range, 0-16), was calculated by adding the taste and smell complaint scores.

Data analysis To assess the significance of the pre/post-rinse differences and the significance of the changes in Fe-induced SLO (delta SLO) over time and treatment periods, repeated measures analysis of variance (ANOVA), which assumes missing data are missing at random and depend on previous measures of the outcome, was used separately for the cancer patients and the healthy subjects. The correlation structure used to model the within patient correlations over time was chosen based on the Bayesian Information Criterion statistic. For treatment periods, data grouping consisted of delta SLO responses at baseline (time 0), during CMT (3- and 6-week time points; averaged within a person across those times), post-CMT (10-week time point), and during adjuvant monthly temozolomide (18- and 30-week time points; averaged within a person across those times). Subjects with missing data at one of the two time periods were included, and the one value was used at the average. Comparisons among baseline, CMT, and the early post-CMT periods included at least 16 of the 17 patients. The later post-CMT period ( 18 or 30 weeks) included 13 patients.

Delta SLO was the arithmetic difference between the measured salivary TBARS before (control) and after (ferrous) oral rinse with ferrous-spiked water. For the salivary parameters, comparative analyses were performed on the mean responses (averaged within subjects across time) between the healthy subjects and cancer patients using Student's $t$ test with or without a Satterthwaite correction, depending on the equality of variances in the two groups. For chemosensory assessment in cancer patients, repeated measures models, as described above, were used to assess the significance of time and treatment on self-reported taste and smell abnormalities as quantified by the CSC scores. Statistical software programs, JMP 9.0 and SAS (SAS, Cary, NC), were used for the data analyses. For all analyses, $p$ values less than 0.05 were considered statistically significant.

\section{Results}

$\mathrm{Fe}$-induced salivary oxidative stress response SLO levels before the oral rinse with ferrous-spiked water did not change 
significantly over time for either the cancer patients or the healthy subjects. Mean levels and standards deviations (mean \pm SD), in micromolars TBARS per gram of protein, ranging from $0.47 \pm 0.45$ to $1.06 \pm 1.22$ for the cancer patients $(p=0.14)$ and from $0.27 \pm 0.21$ to $0.43 \pm 0.46$ in healthy subjects ( $p=$ $0.73)$. Mean levels were higher for cancer patients at every time, and on average, the mean level in cancer patients was significantly greater than that of healthy subjects $(0.80 \pm 0.71$ vs. $0.35 \pm 0.14, p=0.020$ ). Similarly, SLO levels after the ferrous rinse did not change significantly over time in either the cancer patients $(p=0.059)$ or the healthy subjects $(p=$ 0.587 ), although the mean increase of over 5 units from 6 to 10 weeks in cancer patients was interesting. On average, the SLO levels after the ferrous rinse were nonsignificantly higher

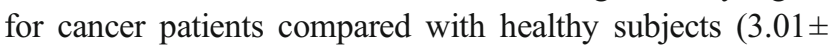
4.06 vs. $1.14 \pm 0.46, p=0.078$ ). The between-subject variability was surprisingly high at 10 - and 18 -week time points, with respective means and standard deviations of $6.60 \pm 9.83$ and $6.60 \pm 12.83$.

Delta SLO represents the Fe-induced SLO response calculated by the arithmetic difference between the measured salivary TBARS before (control) and after (ferrous) oral rinse with ferrous-spiked water. Changes in the delta SLO levels over time as well as during cancer treatment were highly variable for the cancer patients, with mean levels ranging from 0.22 to $5.91 \mu \mathrm{M}$ TBARS/g protein; changes in the delta SLO over time were much more consistent for the healthy subjects with mean delta SLO ranging from 0.67 to $0.88 \mu \mathrm{M}$ TBARS/g protein. The change in delta SLO over time was not statistically significant for either the healthy subjects $(p=0.98)$ or the cancer patients $(p=0.11)$. Likewise, when mean delta SLO responses for the cancer patients were evaluated by treatment phase, the differences were non-significant $(p=0.16)$.

At each time point, mean SLO levels typically increased after oral rinse with ferrous-spiked water in both cancer patients and healthy subjects. The increase in mean SLO after ferrous rinse was consistently significant in healthy subjects ( $p \leq 0.005$ for all times), while the increase for cancer patients was significant at all times $(p<0.029)$ except 6 weeks $(p=$ $0.410)$. The increase in SLO response after oral rinse with ferrous-spiked water corresponded with perception of a strong metallic sensation in the mouth as verbally described by both subject groups. The metallic sensation was absent or barely perceived when subjects' nostrils were closed using nose clips, indicative of a retronasal perception phenomenon as described by other researchers $[17,35]$.

Chemosensory assessment Self-reported taste and smell abnormalities for individual cancer patients, as assessed by the CSC score scale of 0 to 16 (none to maximal impairment), ranged from 0 to 15 . CSC scores for cancer patients as plotted against time in weeks and treatment phase are displayed in
Fig. 2. Changes in CSC scores, mean $\pm \mathrm{SD}$, were significant over time from 3 to 30 weeks $(1.6 \pm 2.4,4.6 \pm 4.1,5.1 \pm 4.1,3.6$ $\pm 3.4,4.4 \pm 4.1$, and $2.3 \pm 4.2, p=0.04$; Fig. $2 \mathrm{a}$ ) as well as treatment $(p=0.03 ;$ Fig. $2 b)$. For the time effect, the significant mean differences were between the baseline (time 0 ) and all the times, except 30 weeks. At baseline and each corresponding time point, the numbers of patients reporting taste complaints were $7,9,12,9,6$, and 4 . The taste complaint scores ranged from a minimum of 0 and mean of $1.2 \pm 1.9$ at baseline to a maximum of 10 and mean of $3.5 \pm 2.7$ at 6 -week time point. The smell complaint scores ranged from a minimum of 0 and mean of $0.5 \pm 1.0$ at baseline to a maximum of 5 and mean of $1.7 \pm 1.9$ at 10 weeks and mean of $1.9 \pm 2.1$ at 18 weeks time points. A majority of the patients (14 out of 17) reported having both taste and smell complaints at some point during the treatment while three patients reported having only taste complaints.

Salivary protein The changes over time in mean total salivary protein levels [before (control) and after the ferrous rinse] were not statistically significant for healthy subjects or cancer patients. Also, the changes over treatment phases for the cancer patients were not significant ( $p>0.05$ for all tests). Salivary protein levels, as averaged across all times, are shown in Fig. 3(c (control), d (ferrous)). The mean control salivary protein levels in $\mathrm{g} / \mathrm{L}$, averaged across time within a subject, were significantly greater for cancer patients compared with healthy controls $(1.42 \pm 0.54$ vs. $0.89 \pm 0.19 ; p=0.001)$. The mean ferrous salivary protein level in grams per liter was also higher for cancer patients, though not significantly so (1.22 \pm 0.52 vs. $0.96 \pm 0.24 ; p=0.08$ ). The mean total salivary protein levels decreased significantly pre- to post-ferrous rinse for cancer patients $(p=0.005)$ but not for healthy controls $(p=$ 0.247).

Measurements of oral $\mathrm{pH}$ Control and ferrous oral $\mathrm{pH}$ levels showed no significant changes over time in either group. Control sample oral $\mathrm{pH}$ levels (averaged across time within subjects) were significantly lower in cancer patients than in healthy subjects $(6.29 \pm 0.46$ vs. $6.70 \pm 0.23 ; p=0.003$; Fig. 3(a)). Ferrous sample $\mathrm{pH}$ levels did not differ significantly between groups $(6.58 \pm 0.44$ vs. $6.69 \pm 0.23 ; p=0.38$; Fig. 3(b)). The change in oral $\mathrm{pH}$ levels (comparing saliva samples before and after ferrous rinse) was statistically significant for cancer patients $(p=0.04)$ but not for healthy subjects $(p=0.61)$.

Salivary metals, nonmetals, and electrolytes In cancer patients, the concentrations of salivary constituents showed no statistically significant changes over time ( $p=0.06$ to 0.81 ) or by treatment $(p=0.12$ to 0.93$)$. For the healthy subjects the mean change in the salivary constituents was significant over time only for $\mathrm{Cu}(p=0.005)$, zinc $(\mathrm{Zn} ; p=0.02)$, and $\mathrm{Fe}$ 
a

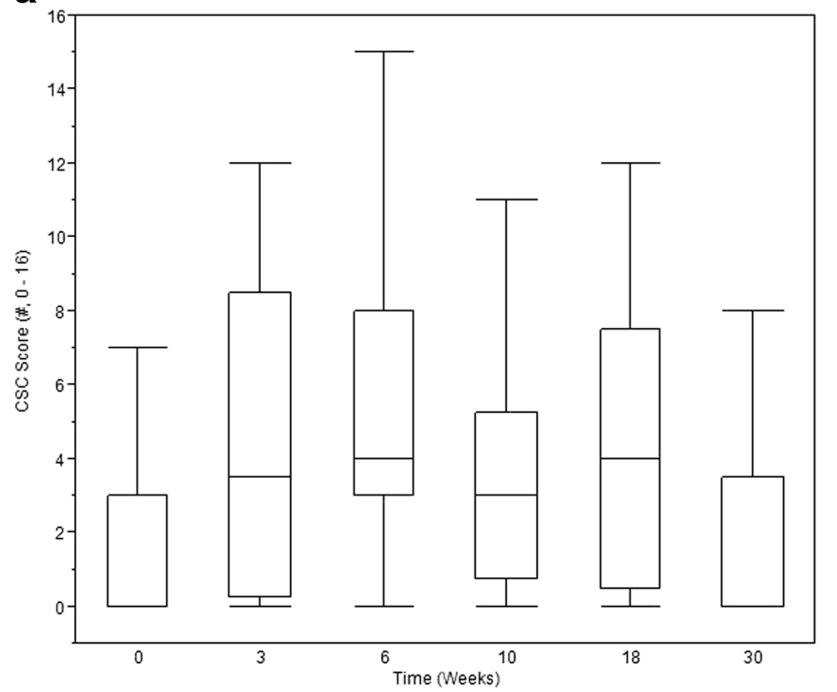

b

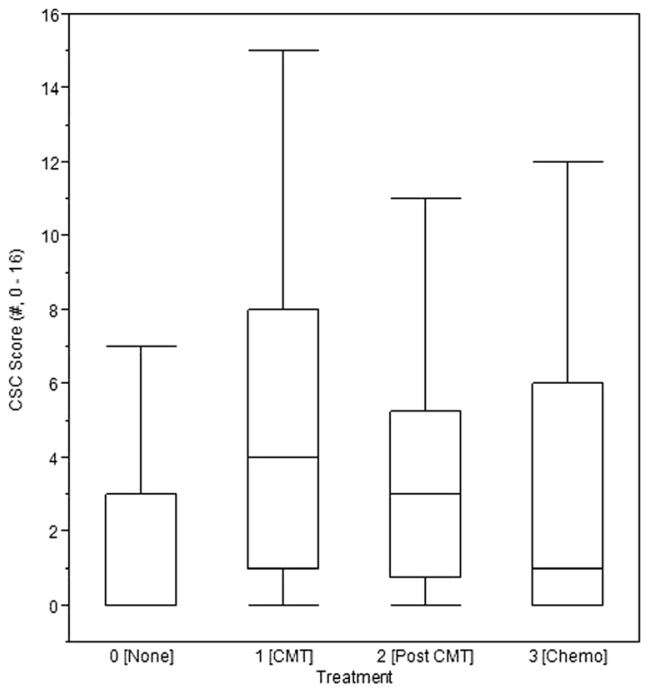

Fig. 2 Chemosensory complaint scores $(C S C)$ for cancer patients $(N=17)$ as measured by self-reported taste and smell questionnaire. The plotted data represent CSC scores over time (a) and the course of the cancer treatment (b)

$(p<0.0001)$. While copper levels showed no clear pattern over time, $\mathrm{Zn}$ and $\mathrm{Fe}$ levels tended to decrease over time. Although changes in salivary $\mathrm{Zn}$ and Fe between subjects and over time could be associated with nutritional status of individuals [36], reasons for this declining trend were not explored. Except for chloride $(\mathrm{Cl})$ and $\mathrm{Ca}$, the mean levels of all constituents (averaged within patients across time) differed significantly between cancer patients and healthy subjects (Table 1). Mean salivary levels of sodium $(\mathrm{Na})$, magnesium $(\mathrm{Mg})$, phosphorus $(\mathrm{P})$, sulfur $(\mathrm{S})$, potassium $(\mathrm{K})$, and $\mathrm{Cu}$ were greater for cancer patients than for healthy subjects while $\mathrm{Zn}$ and $\mathrm{Fe}$ levels (both before and after ferrous rinse) were significantly lower for cancer patients than for healthy subjects.
Fig. 3 Comparisons of mean levels of oral $\mathrm{pH}(a, b)$ and total salivary protein levels $(c, d)$ in cancer patients $(N=17)$ and healthy subjects $(N=22)$

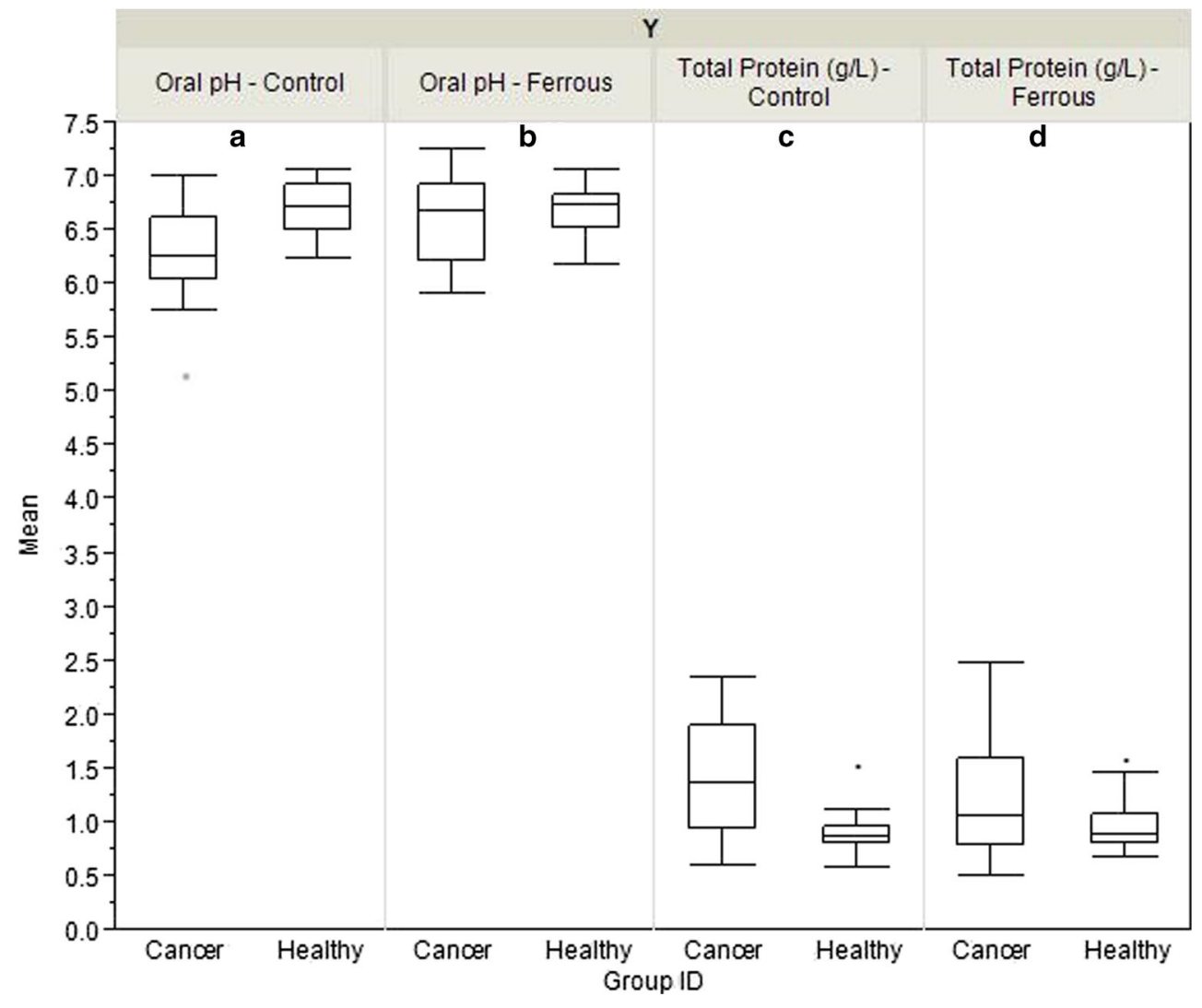


Table 1 Comparison of salivary electrolytes, metals, and nonmetals in cancer patients and healthy subjects

\begin{tabular}{|c|c|c|c|}
\hline \multirow[t]{2}{*}{ Salivary parameter } & \multicolumn{2}{|c|}{ Measured concentration (mg/L: mean \pm standard deviation $(95 \% \mathrm{CI})$ ) } & \multirow{2}{*}{$\begin{array}{l}\text { Means comparison } \\
p \text { value }\end{array}$} \\
\hline & Cancer group & Healthy group & \\
\hline \multicolumn{4}{|l|}{ Elements (total) } \\
\hline $\mathrm{Na}$ & $211.28 \pm 49.02(186.08-236.48)$ & $169.23 \pm 41.11(151.00-187.46)$ & 0.006 \\
\hline $\mathrm{Mg}$ & $8.69 \pm 0.55(7.54-9.85)$ & $5.49 \pm 1.35(4.89-6.09)$ & $<0.0001$ \\
\hline $\mathrm{P}$ & $222.67 \pm 59.21(192.23-253.11)$ & $166.69 \pm 47.45(145.65-187.73)$ & 0.002 \\
\hline $\mathrm{S}$ & $346.33 \pm 87.86(301.16-391.50)$ & $237.98 \pm 44.61(218.20-257.76)$ & $<0.0001$ \\
\hline $\mathrm{Cl}$ & $621.57 \pm 170.77(533.76-709.37)$ & $553.20 \pm 98.24(509.64-596.76)$ & 0.12 \\
\hline $\mathrm{K}$ & $1088.40 \pm 245.74(962.02-1214.70)$ & $776.28 \pm 130.81(718.28-834.27)$ & $<0.0001$ \\
\hline $\mathrm{Ca}$ & $74.46 \pm 19.04(64.67-84.24)$ & $67.04 \pm 13.08(61.24-72.85)$ & 0.16 \\
\hline $\mathrm{Cu}$ & $0.09 \pm 0.04(0.07-0.11)$ & $0.06 \pm 0.04(0.04-0.08)$ & 0.05 \\
\hline $\mathrm{Zn}$ & $0.41 \pm 0.17(0.32-0.49)$ & $0.54 \pm 0.12(0.49-0.60)$ & 0.005 \\
\hline $\mathrm{Fe}$ (before $\mathrm{Fe}^{+2}$ rinse) & $0.49 \pm 0.12(0.43-0.55)$ & $1.28 \pm 0.21(1.19-1.37)$ & $<0.0001$ \\
\hline $\mathrm{Fe}$ (after $\mathrm{Fe}^{+2}$ rinse) & $1.96 \pm 0.39(1.76-2.17)$ & $3.68 \pm 0.23(3.58-3.78)$ & $<0.0001$ \\
\hline
\end{tabular}

${ }^{\text {a }}$ Comparison of the overall mean of the salivary parameters between the healthy subjects $(n=22)$ and cancer patients $(n=17)$, as averaged across all times, within subjects

\section{Discussion}

Our results show that in this group of cancer patients, the impact of CMT on impairment of chemosensory functions was significant; however, chemosensory impairment, as assessed over the course of treatment, did not necessarily coincide with $\mathrm{Fe}$-induced salivary oxidative stress response and other measured saliva constituents. Conversely, the significant differences in multiple salivary parameters between cancer patients and healthy subjects can provide clues on the causes and/or identify potential biomarkers of chemosensory disorders, as highlighted in Table 2. The findings are further discussed in the proceeding sections.

Salivary oxidative stress response and chemosensory assessment The overall mean SLO levels in control saliva samples collected before oral rinse with ferrous-spiked drinking water was significantly higher in cancer patients than in healthy subjects. Elevated oxidative stress response in biological fluids such as serum and saliva is a common occurrence in some disease conditions including cancer [37, 38]. The increase in oxidative stress response is associated with freeradical reactions that cause damage to macromolecular components, such as lipids, proteins, and DNA in cells and tissues [39]. Transition metals, such as Fe, are known for their catalytic effects on free-radical oxidative reactions [40]; therefore, the higher mean SLO responses in cancer patients and healthy subjects is not surprising after oral rinse with ferrous-spiked water. The overall increase in the intensity of Fe-induced oxidative stress response was somewhat consistent with the chemosensory responses as measured by the mean CSC scores, which increased significantly with respect to time and treatment $(p<0.05)$ as compared with the baseline; however, the findings were not uniform. For example, in some cancer patients, the mean CSC scores were parallel to that of the Fe-induced oxidative stress response as measured by delta SLO, whereas in other patients the Fe-induced oxidative stress response did not correspond with the CSC scores. By contrast, prior to the start of cancer treatment (at baseline or time 0 ), Feinduced SLO and CSC scores in cancer patients showed a relatively strong linear correlation $\left(R^{2}=0.84 ; p<0.0001\right)$, no such correlation existed at time points ( 3 through 30 weeks) during the treatment ( $R^{2}$ ranging from 0.0003 to 0.06 ). This finding indicates that although Fe-induced SLO can be used as an indicator of sensory response to metallic flavor perception in both healthy subjects and cancer patients, it is not a reliable biomarker of chemosensory impairment associated with cancer therapy in glioma patients.

On the persistence of self-reported taste and smell abnormalities as measured by the CSC scores obtained using a validated questionnaire, our results are consistent with previous findings. Namely, a study in patients with breast cancer or gynecological malignancies showed that taste and smell functions, as assessed by sniff sticks and taste strips, declined significantly during chemotherapy, but normal functioning returned 3 months after chemotherapy [41]. In our study, sensory abnormalities occurred and persisted during cancer treatment but returned to the baseline levels 30 weeks after the start of treatment. As a limitation, the quantified taste complaint scores in our study assessed the patients' self-reported complaints associated with rating of persistent, unpleasant and/or abnormal tastes in the mouth, and the presence or absence of abnormal sensitivity to the taste sensations of salty, sweet, sour, and bitterness. Therefore, the quantified 


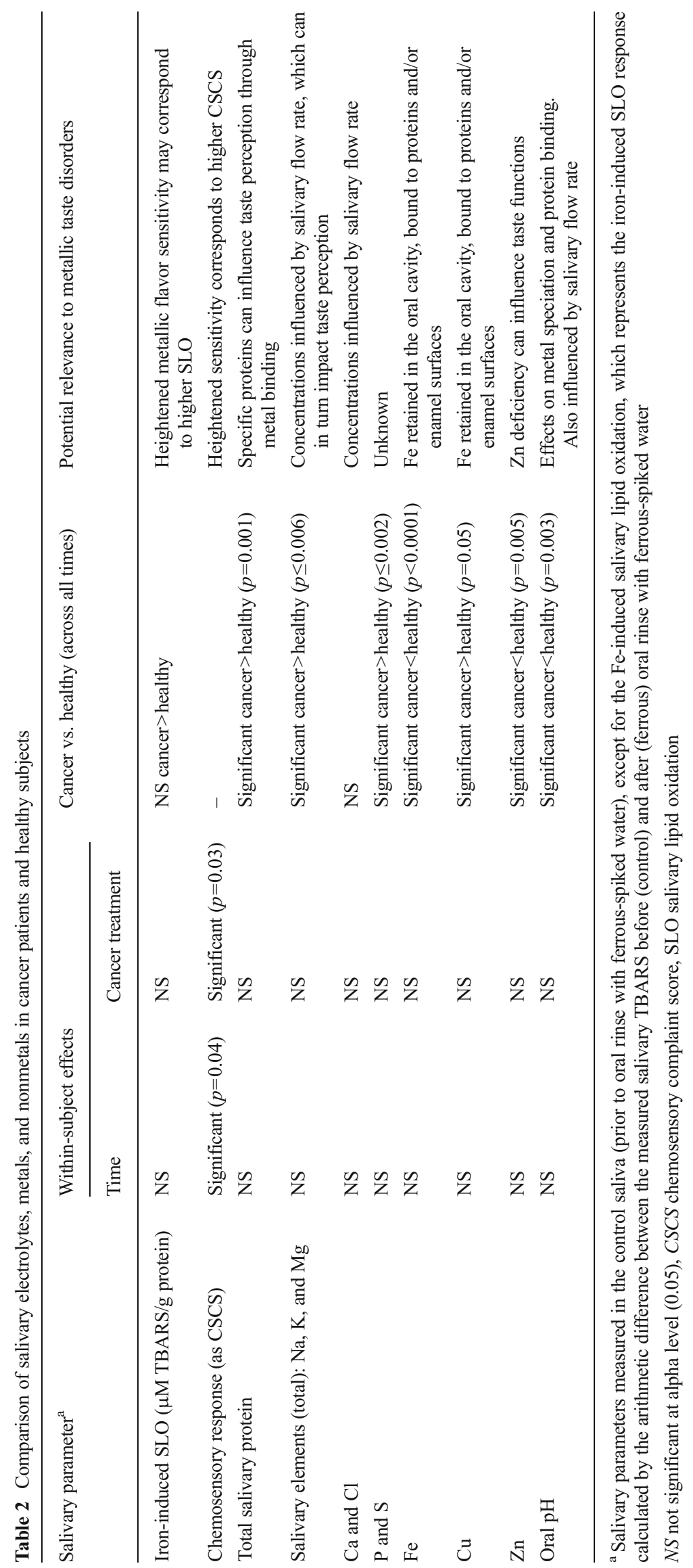


chemosensory complaint scores are not exclusively indicative of metallic flavor complaints. However, the heightened sensitivity to metallic sensation was qualitatively assessed through patients' verbal descriptors of strongly perceived metallic sensation and the corresponding measure of salivary oral lipid oxidation responses before and after oral rinse with ferrousspiked water. The strongly metallic flavor was perceived only with the nose open. This is indicative of the patients' abilities to perceive the metal-induced retronasal smell, as partly reflected by the lower occurrence of self-reported smell complaints relative to taste complaints. A previous study evaluating age-related sensitivities to metallic flavor of $\mathrm{Fe}$ in healthy adults associated impaired olfactory functions with a diminished sensitivity to metallic flavor [16].

Another limitation is the small sample size for cancer patients and the fact that not all patients were able to provide data at each time point. No patient had complete data and four patients dropped out of the study after 10 weeks.

Variations in oral $p H$ and potential influence on taste perception As presented earlier, our results indicate that the mean oral $\mathrm{pH}$ level in cancer patients was significantly lower $(p<0.0001)$ than that of healthy subjects. As $\mathrm{pH}$ is an important factor in speciation of metals in aqueous environments, variations in $\mathrm{pH}$ could be an implicating factor in taste perception. A previous study on $\mathrm{Cu}$ has shown that taste perception is associated with soluble species of $\mathrm{Cu}$ and that the particulate form, which generally forms above $\mathrm{pH} 7$, is poorly tasted [42]. In the case of $\mathrm{Fe}$, within the typical $\mathrm{pH}$ range of saliva (5.5-8.0), Fe is expected to remain in the dissolved ferrous form [43]. In the presence of salivary proteins, the role of $\mathrm{pH}$ can be further complicated. Studies with artificial saliva have shown that the metal-binding capacities of major salivary proteins, mucin and alpha amylase, can decrease or increase based on the metal concentration as well as the salivary $\mathrm{pH}$ [44]. Additionally, depending on their isoelectric points in relation to the $\mathrm{pH}$ of saliva, different salivary proteins can be influenced to either inhibit or enhance lipid oxidation reactions [45].

Salivary metals, nonmetals, and electrolytes As a noninvasive method of biological sample collection, analysis of salivary fluid for metals and electrolytes has been extensively studied in the literature for the purposes of exposure assessment to toxic metals or diagnostics in clinical applications [44, 46]. It is recognized that there are inherently wide variations between and within subjects on salivary parameters due to variations in salivary flow, whereas possibly age and gender could be sources of variations as well [47]. Our research showed that mean levels of salivary electrolytes, metals and nonmetals, specifically, $\mathrm{Na}, \mathrm{Cl}, \mathrm{K}, \mathrm{Mg}, \mathrm{P}$, and $\mathrm{S}$ were significantly higher in the cancer patients $(p<0.05)$ when compared with the healthy subjects, whereas the mean level of total $\mathrm{Zn}$ and Fe was significantly lower in the cancer patients than healthy subjects $(p<0.0001)$.

Zn deficiency has been widely associated with decline in taste acuity, although the findings are conflicting. In a clinical study with a group of head and neck cancer patients [48], it was demonstrated that oral administration of $\mathrm{Zn}$ sulfate alleviated taste abnormalities in cancer patients treated with external beam radiation therapy and improved the recovery of their taste acuity after the treatment. Similar findings have been reported in other studies [46], whereas in other cases $\mathrm{Zn}$ supplementation failed to prevent taste alterations in head and neck cancer patients undergoing radiotherapy as demonstrated in a placebo-controlled trial [49].

One interesting finding from our study is the consistently significant lower level of $\mathrm{Fe}$ in saliva of cancer patients compared with that of healthy subjects $(p<0.0001)$. This observation remained even after the oral rinse with drinking water containing $10 \pm 1 \mathrm{mg} / \mathrm{L}$ of ferrous sulfate, indicative of significantly lower recovery of $\mathrm{Fe}$ in saliva of cancer patients after the oral rinse with ferrous sulfate.

A possible reason for the observed low Fe levels in saliva of cancer patients relative to the healthy subjects could be associated with nutritional state of the patients. Among side effects of chemotherapy, conditions of anemia and Fe deficiency are common and often treated with Fe supplementation or therapeutic agents that boost red blood cells production [50, 51].

As expected, the concentration of total $\mathrm{Fe}$ recovered in saliva after oral rinse with ferrous-spiked water was higher than the pre-rinse concentrations; however, the notably low post-rinse recovery of $\mathrm{Fe}$ from the saliva of the cancer patients as compared with the healthy subjects is puzzling. In exploring possible reasons for this low recovery, the loss of Fe could be associated with the rapid uptake of Fe by Fe-binding proteins that were not recovered in the expectorated saliva, accidental swallowing of the Fe-spiked oral rinse water, and binding of the protein-complexed Fe to oral cavity tissues and/ or teeth surfaces. Dental research has shown that a number of salivary proteins, namely proline-rich proteins, cystatins, statherin, and histatins selectively bind to enamel surfaces and hydroxyapatite [52]. Additionally, radiation therapies targeting tumors in the head and neck region have been shown to influence salivary protein composition [53]. Thus, variations in individual salivary protein compositions between cancer and healthy subjects could indirectly influence the post-rinse recovery of Fe from saliva.

\section{Conclusions}

For the malignant glioma patients in this study, the results did not show trends in salivary lipid oxidation, total proteins, or levels of individual metals in saliva over the course of their 30- 
week cancer treatment. These three salivary parameters also did not provide for reliable measures of chemosensory dysfunctions over time. When compared with the saliva of healthy subjects, the malignant glioma patients had significantly higher levels of salivary lipid oxidation, total protein, and $\mathrm{Na}, \mathrm{Cl}, \mathrm{K}, \mathrm{Mg}, \mathrm{P}$, and $\mathrm{S}$; patients had statistically lower levels of salivary Fe and Zn. Implications of this study are that the differences in salivary constituents for malignant glioma patients should be further explored to find their causes and that further research into sources of chemosensory dysfunction are warranted.

Additionally, our findings identify a need to distinguish and quantify chemosensory dysfunction in cancer patients based on sensitivity to basic tastes and metallic stimuli, as the latter is dominated by retronasal smell rather than taste functions.

Acknowledgments The authors acknowledge the Institute for Critical Technology and Applied Science at Virginia Tech, the Comprehensive Cancer Center of the Wake-Forest School of Medicine, and Virginia Tech's Water INTERface Interdisciplinary Graduate Education Program for funding support. Special acknowledgment is given to all the human subjects for their participation. The authors thank the Oncology staff at the Wake Forest University School of Medicine for saliva sample and sensory data collection. The authors appreciate the assistance of their undergraduate researchers, Mr. Timothy Smiley and Mr. Shannon Flynn, for their laboratory support. The authors appreciate the scientific input and technical support from their Virginia Tech colleagues: Drs. Dan Gallagher, Greg Boardman, Brenda Davy, Henjian Wang, Yong-Woo Lee, Jeff Parks, Ms. Jodie Smiley, Ms. Julie Petruska, Ms. Kerri Martin, and Ms. Kim Waterman. The authors acknowledge support from the Virginia Tech's Open Access Subvention Fund to finance open access publication.

Conflict of interest The authors declare that they have no conflict of interest.

Open Access This article is distributed under the terms of the Creative Commons Attribution License which permits any use, distribution, and reproduction in any medium, provided the original author(s) and the source are credited.

\section{References}

1. Ackerman BH, Kasbekar N (1997) Disturbances of taste and smell induced by drugs. Pharmacotherapy 17(3):482-496

2. Bernhardson B, Tishelman C, Rutqvist L (2007) Self-reported taste and smell changes during cancer chemotherapy. Support Care Cancer 16:275-83. doi:10.1007/s00520-007-0319-7

3. Boyce JM, Shone GR (2006) Effects of ageing on smell and taste. Postgrad Med J 82(966):239-241

4. Bromley SM (2000) Smell and taste disorders: a primary care approach. Am Fam Physician 61(2):427-436

5. Deems DA, Doty RL, Settle G, Mooregillon V, Shaman P, Mester AF et al (1991) Smell and taste disorders, a study of 750 patients from the university-of-Pennsylvania smell and taste center. Arch Otolaryngol Head Neck Surg 117(5):519-528

6. Doty RL (2009) The olfactory system and its disorders. Semin Neurol 29(1):74-81

7. Dewys WD, Walters K (1975) Abnormalities of taste sensation in cancer patients. Cancer 36(5):1888-1896
8. Di Fiore F, Rigal O (2009) Chemotherapy-induced oral food intake impairment. Oncologie 11(4):204-210

9. McDaniel RRV (1998) Development of a preparatory sensory information videotape for women receiving chemotherapy for breast cancer. Cancer Nurs 21:143-148

10. Skolin I, Wahlin YB, Broman DA, Hursti UKK, Larsson MV, Hernell O (2006) Altered food intake and taste perception in children with cancer after start of chemotherapy: perspectives of children, parents and nurses. Support Care Cancer 14(4):369-378

11. de Graeff A, de Leeuw JRJ, Ros WJG, Hordijk GJ, Blijham GH, Winnubst JAM (2000) Long-term quality of life of patients with head and neck cancer. Laryngoscope 110(1):98-106

12. Hong J-H, Ömür-Özbek P, Stanek BT, Dietrich AM, Duncan SE, Lee YW, Lesser G (2009) Taste and smell abnormalities in cancer patients. J Support Oncol 7(2):58-65

13. Epstein JB, Phillips N, Parry J, Epstein MS, Nevill T, StevensonMoore P (2002) Quality of life, taste, olfactory and oral function following high-dose chemotherapy and allogeneic hematopoietic cell transplantation. Bone Marrow Transplant 30(11):785-792

14. McGowan D (2008) Chemotherapy-induced oral dysfunction: a literature review. Br J Nurs 17(22):1422-1426

15. Lawless HT, Shlake S, Smythe J, Lim J, Yang H, Chapman K et al (2004) Metallic taste and retronasal smell. Chem Senses 29(1):25-33

16. Mirlohi S, Dietrich AM, Duncan SE (2011) Age-associated variation in sensory perception of iron in drinking water and the potential for overexposure in the human population. Environ Sci Technol 45(15): $6575-6583$

17. Hong JH, Kim KO (2011) Operationally defined solubilization of copper and iron in human saliva and implications for metallic flavor perception. Eur Food Res Technol 233(6):973-983

18. Ömur-Özbek P, Dietrich AM, Duncan SE, Lee Y (2012) Role of lipid oxidation, chelating agents, and antioxidants in metallic flavor development in the oral cavity. J Agric Food Chem 60(9):2274-2280

19. Glindemann D, Dietrich AM, Staerk HJ, Kuschk P (2006) The two smells of touched or pickled iron (skin) carbonyl-hydrocarbons and organophosphines. Eur J Appl Chem [Angewandte chemie Intl] 45: 7006-7009

20. Larsson B, Olivecrona G, Ericson T (1996) Lipids in human saliva. Arch Oral Biol 41(1):105-110

21. Comeau TB, Epstein JB, Migas C (2001) Taste and smell dysfunction in patients receiving chemotherapy: a review of current knowledge. Support Care Cancer 9(8):575-580

22. Capra S, Ferguson M, Ried K (2001) Cancer: impact of nutrition intervention outcome - nutrition issues for patients. Nutr Res 17: 769-772

23. Ravasco P (2005) Aspects of taste and compliance in patients with cancer. Eur J Oncol Nurs 9:84-91

24. Epstein JB, Barasch A (2010) Taste disorders in cancer patients: pathogenesis, and approach to assessment and management. Oral Oncol 46(2):77-81

25. Logan HL, Bartoshuk LM, Fillingim RB, Tomar SL, Mendenhall WM (2008) Metallic taste phantom predicts oral pain among 5-year survivors of head and neck cancer. Pain 140(2):323-331

26. Mirza N, Machtay M, Devine PA, Troxel A, Abboud SK, Doty RL (2008) Gustatory impairment in patients undergoing head and neck irradiation. Laryngoscope 118(1):24-31

27. Stupp R, Mason W, van den Bent M, Weller M, Fisher B, Taphoorn $M$ et al (2005) Radiotherapy plus concomitant and adjuvant temozolomide for glioblastoma. N Engl J Med 352:987-996

28. National Cancer Institute at the National Institute of Health (2013). Fact Sheet on Head and Neck Cancers. Website, http://www.cancer. gov/cancertopics/factsheet/Sites-Types/head-and-neck. Accessed 8 July 2013

29. American Brain Tumor Association. (2013). Brain Tumor Facts, web site: www.abta.org. Accessed 8 July 2013 
30. Lesser G, Case D, Mirlohi S, Harmon M, Chan M, Duncan S, Dietrich A (2011) Taste and smell abnormalities (TSA) in patients with newly diagnosed malignant gliomas (MG) treated with combined modality therapy (CMT). Proc ASCO Annu Meet J Clin Oncol 29:2011, suppl; abstr e19646

31. Spanier AM (1991) A rapid, direct chemical assay for the quantitative determination of thiobarbituric acid reactive substances in raw, cooked, and cooked/stored muscle foods. J Muscle Foods 2(3): $165-175$

32. Copeland RA. (1994). Methods for protein quantification.Chap.3.: Methods for Protein Analysis: A Practical Guide to Laboratory Protocols. In: Chapman and Hall (Ed), New York, NY, pp 39-58

33. U.S. Environmental Protection Agency, Office of Solid Waste and Emergency Response. (1996). Test Methods for Evaluating Solid Waste, SW-846, 3rd ed., Method 3050B. http://www.epa.gov/osw/ hazard/testmethods/sw846/pdfs/3050b.pdf

34. Hutton JL, Baracos VE, Wismer WV (2007) Chemosensory dysfunction is a primary factor in the evolution of declining nutritional status and quality of life in patients with advanced cancer. J Pain Symptom Manag 33(2):156-165

35. Dietrich AM (2009) The sense of smell: contributions of orthonasal and retronasal perception applied to metallic flavor of drinking water. J Water Supply Res Technol AQUA 58(8):562-570

36. Yadrick MK, Kenney MA, Winterfeldt EA (1989) Iron, copper, and zinc status: response to supplementation with zinc or zinc and iron in adult females. Am J Clin Nutr 49(1):145-150

37. Adibhatla RM, Hatcher JF (2010) Lipid oxidation and peroxidation in CNS health and disease: from molecular mechanisms to therapeutic opportunities. Antioxid Redox Signal 12(1):125-169

38. Angeli JPF, Garcia CCM, Sena F, Freitas FP, Miyamoto S, Medeiros MHG et al (2011) Lipid hydroperoxide-induced and hemoglobinenhanced oxidative damage to colon cancer cells. Free Radic Biol Med 51(2):503-515

39. Catala A (2009) Lipid peroxidation of membrane phospholipids generates hydroxy-alkenals and oxidized phospholipids active in physiological and/or pathological conditions. Chem Phys Lipids 157(1):1-11

40. Jomova K, Valko M (2011) Advances in metal-induced oxidative stress and human disease. Toxicology 283(2-3):65-87

41. Steinbach S, Hummel T, Bohner C, Berktold S, Hundt W, Kriner M et al (2009) Qualitative and quantitative assessment of taste and smell changes in patients undergoing chemotherapy for breast cancer or gynecologic malignancies. J Clin Oncol 27(11):1899-1905

42. Cuppett JD, Duncan SE, Dietrich AM (2006) Evaluation of copper speciation and water quality factors that affect aqueous copper tasting response. Chem Senses 31(7):689-697

43. Benjamin MM. (2002). Water Chemistry, 1st ed.: McGraw-Hill

44. Tang, Jia, (2010), MS Thesis: Modeling Contaminant Transport in Polyethylene and Metal Speciation in Saliva; Virginia Tech, Blacksburg Virginia, A.M. Dietrich, Advisor

45. Elias RJ, Kellerby SS, Decker EA (2008) Antioxidant activity of proteins and peptides. Crit Rev Food Sci Nutr 48(5): 430-441

46. Watanabe M, Asatsuma M, Ikui A, Ikeda M, Yamada Y, Nomura S et al (2005) Measurements of several metallic elements and matrix metalloproteinases (MMPs) in saliva from patients with taste disorder. Chem Senses 30(2):121-125

47. Wang DX, Du XQ, Zheng W (2008) Alteration of saliva and serum concentrations of manganese, copper, zinc, cadmium and lead among career welders. Toxicol Lett 176(1):40

48. Ripamonti C, Zecca E, Brunelli C, Fulfaro F, Villa S, Balzarini A et al (1998) A randomized, controlled clinical trial to evaluate the effects of zinc sulfate on cancer patients with taste alterations caused by head and neck irradiation. Cancer 82(10):1938-1945

49. Halyard M, Jatoi A, Sloan J, Bearden J, Fitch T, Atherton P, Buskirk S, Soori G, Kugler J, Loprinzi L et al (2006) Does zinc sulfate to prevent radiation-induced taste alterations ("dysgeusia") in head and neck cancer patients? a north central cancer treatment group (NCCT G) placebo-controlled trial [abstract]. I J Radiat Oncol Biol Phys 55(3):S414

50. Cunningham RS (2003) Anemia in the oncology patient-cognitive function and cancer. Cancer Nurs 26(6):38S-42S

51. Steinmetz HT, Tsamaloukas A, Schmitz S, Wiegand J, Rohrberg R, Eggert J et al (2011) A new concept for the differential diagnosis and therapy of anaemia in cancer patients. Support Care Cancer 19(2): 261-269

52. Lamkin MS, Arancillo AA, Oppenheim FG (1996) Temporal and compositional characteristics of salivary protein adsorption to hydroxyapatite. J Dent Res 75(2):803-8

53. Hannig M, Dounis E, Henning T, Apitz N, Stößer L (2006) Does irradiation affect the protein composition of saliva? Clin Oral Investig 10(1):61-65 